\title{
Identifying Price-Leadership Structures in Oligopoly
}

\author{
Sang-Hyun Kim ${ }^{\text {a }}$, Hao Lan ${ }^{b}$, and Paul W. Dobson ${ }^{c}$

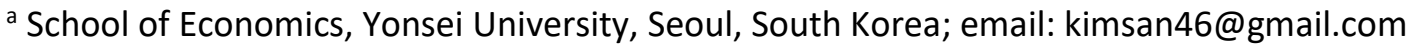 \\ b International Business School Suzhou, Xi'an Jiaotong-Liverpool University, Suzhou, P.R. China; \\ email: Hao.Lan@xjtlu.edu.cn (corresponding author) \\ ${ }^{c}$ Norwich Business School and Centre for Competition Policy, University of East Anglia, Norwich, UK; \\ email: p.dobson@uea.ac.uk
}

\begin{abstract}
Oligopoly can give rise to complex patterns of price interaction and adjustment. While oligopolistic firms may divide into price leaders and price followers, it is conceivable that some may take on dual roles, being a leader to one group but a follower to a different group in a hierarchical structure. The contribution of this paper is to show how such dual relationships are possible in theory along with providing an empirical method to help identify price-leadership structures in $n$-firm oligopoly. As an illustration, we apply the method to British supermarkets and find a three-tier leader-follower structure.
\end{abstract}

JEL classifications: D43, L13, L41, L81 


\section{Introduction}

In contrast to the majority of theoretical models of price competition, markets in the real world rarely operate as a simultaneous move game with price adjustments undertaken as completely hidden actions until jointly revealed. Instead, firms post and alter their prices in continuous time, responding to changes in production/operation costs and rivals' posted prices. While it is rather well understood that non-simultaneity of price changes can facilitate coordination among competing firms, thus may elevate prices and reduce consumer welfare, existing theory and empirical analysis on price leadership focuses on a dichotomous relationship where a firm is either a price leader or price follower - but not both (at least not at the same time). This is reasonable in a duopoly where there are only two firms, with one firm taking on the role of price leader and the other firm then responding as the price follower. However, when there are more than two firms then other permutations could exist, notably in a hierarchical form such that a firm could be a price leader over some firms but a price follower in respect of other firms. The distinctive and novel contribution of this paper is to show how such dual hierarchical relationships are possible in both theory and practice.

Price leadership models adopt either an exogenously or endogenously determined pricing sequence. The former tend to follow in the spirit of Forchheimer (1908), where a dominant firm acts as a price leader while a competitive fringe passively serve as price followers, or Saving (1970) with a dominant group acting as collusive price leaders. Most of the modern literature, though, focuses on endogenous sequencing, where firms choose whether to lead or follow rivals in setting prices. In the spirit of von Stackelberg (1934), competing firms might wish to avoid being price leaders since there is generally a second-mover advantage in price-setting oligopoly where firms' prices are strategic complements, presenting the opportunity to undercut a price leader and increase market share (Amir and Stepanova 2006). However, if there is sufficient asymmetry combined with some countering benefit in moving first then a price leader might emerge. For example, this could arise when a firm has a market information advantage (Rotemberg and Saloner 1990; Gilpatric and Li 2016), a capacity advantage (Deneckere and Kovenock 1992; Furth and Kovenock 1993), a cost advantage (Ono 1992; van Damme and Hurkens 2004; Amir and Stepanova 2006), a customer loyalty advantage (Deneckere et al. 1992), or superior product quality (Li 2014). Even so, it is not necessarily the case that a dominant or more efficient firm is prepared to serve as the price leader (Tasnádi 2004), it could even be a 
smaller, less efficient firm (Hirata and Matsumura 2011; Mouraviev and Rey 2011). Additionally, roles may switch when there is a cost of delay in making price announcements, with firms mixing the timing of their pricing moves (Pastine and Pastine 2004).

While this theoretical literature extends beyond duopoly, such as examining triopolies (Güth et al. 2014; Tasnádi 2016), the common approach is on the emergence of one price leader (or a colluding group) and all other firms acting as direct price followers. To our knowledge, this paper is the first to show how there can be an endogenously determined succession of firms setting prices in an $n$-firm oligopoly, such that one might lead, followed by a rival, but with that rival then followed by a further rival, and so on, in a hierarchical structure with a cascading sequence of price choices. We formally demonstrate this by extending the competitive duopoly model of Deneckere et al. (1992) to oligopoly, where the firms differ in the sizes of their loyal customer base, which appears particularly apt in the context of our empirical application examining supermarket retail competition with different degrees of store loyalty and shopper switching behaviour across the set of competing retailers.

Beyond theory, identifying price leadership structures in practice requires the application of a clear, testable definition of price leadership applicable to a wide range of competitive circumstances. In confronting this identification challenge, Seaton and Waterson (2013, hereafter 'SW') proposed a narrow, falsifiable definition of price leadership along with a way to identify empirically a price leader and a follower. The SW method is simple and elegant but is limited because it only applies to two firms, so might be fine for analysing a duopoly but is not geared to identifying relationships between multiple oligopolistic firms, so risks generating misleading results.

This paper provides a more general means for identifying price leadership structures in $n$-firm oligopoly, which we call the Generalized Seaton-Waterson ('GSW') method. This procedure helps to identify price-leadership structures when the market consists of more than two significant players and when there is the possibility of quite complex patterns of pricing dependencies across multiple firms.

To provide a practical illustration in how to apply our GSW method, we intentionally follow SW in examining pricing amongst British supermarket retailers - representing a sector regularly under the watchful gaze of competition authorities with concerns about ineffective competition and price coordination (e.g. Competition Commission 2000; 2003; 2008; Chakraborty et al. 2014; Thomassen et al. 2017). As a complement to SW's analysis on packaged grocery products, we instead focus on fresh 
produce and examine the prices of a range of fruit and vegetables matched across all seven large mainstream supermarket retailers in the UK. Specifically, we draw on data used in Lan and Dobson (2017), which examines other pricing issues. Like SW, our data contains weekly collected prices spanning seven years, but slightly later in running from 2007 to 2013, though our prime interest is looking for leader-follower patterns over the entire period rather than for individual years, which is the theme of SW.

Our analysis reveals that the British supermarket sector, at least in terms of these products, has a three-tier structure where the major retailers can be categorized as either the leaders (Asda and Tesco), the first followers (Sainsbury and Morrisons) or the second followers (Marks \& Spencer, Waitrose and Co-operative Food).

In the empirical literature on price leadership, few papers focus on a narrow, falsifiable perspective in the manner of the SW paper. Similar approaches can be found in Wang (2009), Lewis (2012), and Andreoli-Versbach and Franck (2015), but most of the empirical papers building on wellspecified analytical models focus on the gasoline retailing market and Edgeworth cycle patterns. Apart from these papers, the more traditional empirical approach uses Granger causality for identifying price interaction patterns. In terms of grocery retailing, Lloyd (2008) applies such a method to test price leadership in the UK beef retailing market. Additionally, of more direct relevance to UK fresh produce retailing, Revoredo-Giha and Renwick (2012) observe a strengthening price interrelationship between Tesco and Sainsbury, where price responses tend to be more strategic rather than straightforward direct competition. However, rather than just pairwise comparisons, there might be merit in studying how a broader set of rivals interact on pricing, which is the purpose of the study here.

The paper proceeds as follows. Section 2 sets out our theoretical analysis of endogenous price leadership in a competitive oligopoly. Section 3 develops the empirical method for identifying price leadership structures. Section 4 provides an overview of British supermarket competition, outlines the price data, and shows how the size base of store-loyal shoppers differ across the seven mainstream retailers. Section 5 reports on the finding of a three-tier price leadership structure amongst British supermarkets (with a supplementary online appendix providing full details of all tests and different robustness checks along with extensive background information on the market and shopper behaviour). Section 6 concludes. 


\section{Theory}

This section develops a model of price leadership in $n$-firm oligopoly based on firms' differences in the loyalty of their customers, extending the duopoly analysis by Denekere et al. (1992). The novelty of our model is that it explicitly recognizes that similarities between particular firms may matter when there are more than two firms. For instance, a firm targeting high-end consumers would share more consumers with another firm targeting high-end consumers than with those targeting low-end consumers.

\subsection{Model set-up}

The model adopts the following assumptions:

A1. The market has $n(\geq 2)$ sellers, indexed by $i, j=1, \ldots, n, i \neq j$, selling a homogeneous product.

A2. Sellers have the same production costs, set at zero for convenience.

A3. Consumers buy at most one unit of the product with a common maximum willingness to pay $r$.

A4. Consumers fall into two types: loyal consumers, each of whom visits only one seller, and switchers, who visit two sellers and make a purchase at the cheaper price, with the notation that that $L_{i}$ is the number of loyal consumers of seller $i, S_{i j}$ is the number of switchers of sellers $i$ and $j$, and $S_{i}=\sum_{j=1}^{n} S_{i, j}$ with $S_{i, j}=S_{j, i}$ and $S_{i, i}=0 .^{1}$

A5. The sellers are identical in all respects except in their loyal-consumer/switcher ratio (henceforth LS ratio), with $\frac{L_{i}}{S_{i}} \neq \frac{L_{j}}{S_{j}}$ for all $i \neq j$, such that they are strictly ordered and indexed from 1 to $n$ in having the most to least loyal consumer base but which in turn leaves them least to most exposed to being undercut and losing their switcher customers. The ordering is determined in reverse. Seller $n$ has the smallest LS ratio, i.e., $\frac{L_{n}}{S_{n}}<\frac{L_{i}}{S_{i}}$ or equivalently $\frac{L_{n}}{L_{n}+S_{n}}<\frac{L_{i}}{L_{i}+S_{i}}$ for any $i \neq n$. Taking away all potential consumers of seller $n$ (that is, $L_{n}+S_{n}$ ) out of the market, leaves seller $n-1$

\footnotetext{
${ }^{1}$ We assume that consumers who visit more than two sellers are negligible, as in the equilibrium characterized by Burdett and Judd (1983). This fits with the data considered in Section 4 where most consumers undertaking their regular main grocery shopping trips use just one or two retailers, with few using three or more retailers.
} 
with the smallest LS ratio, i.e., $\frac{L_{n-1}}{S_{n-1}-S_{n, n-1}}<\frac{L_{i}}{S_{i}-S_{n, i}}$ for any $i<n-1$. Without those who visit sellers $n$ and/or $n-1$, seller $n-2$ has the smallest ratio (i.e., $\frac{L_{n-2}}{S_{n-2}-S_{n, n-2}-S_{n-1, n-2}}<\frac{L_{i}}{S_{i}-S_{n, i}-S_{n-1, i}}$ for any $i<n-2)$ and so forth through to seller 1 .

A6. The network structure, in which sellers are nodes and switchers are edges, is complete in the sense that every node connects to every other node, ensured by sellers with larger loyal consumer groups having sufficiently many switchers, with $L_{i}+\sum_{k=1}^{j} S_{i, k}>L_{j}+\sum_{k=1}^{j} S_{j, k}$ for all $i<j$, and every pair of sellers sharing at least some switchers, so $S_{i, j}>0$ for all $i$ and $j .^{2}$

A7. The timing of moves is in keeping with the timing commitment game of Hamilton and Slutsky (1990), where there are $n$ opportunities to set a price, and each seller simultaneously and independently makes a commitment to one of them. If a seller, and no other seller, chooses the first opportunity (or slot), she sets her price first. Similarly, if $k-1$ other sellers choose the earlier slots then the seller set her price after the $k-1$ other sellers set theirs. If two or more sellers choose the same slot, their order is randomly determined without affecting the order of pricing before and after them. Randomness is immediately resolved after the sellers' decisions. Thus, when setting the prices all sellers know the determined order of pricing. ${ }^{3}$

A8. There is a cost of delay, which may be due to not announcing the optimal price on time (Deneckere et al., 1992; Pastine and Pastine, 2004). ${ }^{4}$ Specifically, if a seller becomes the $k$-th mover, she pays an additional cost of $(k-1) \varepsilon$ where $\varepsilon(>0)$ is the unit cost of delay. (The cost of delay serves to eliminate multiple equilibria by ensuring that sellers will not delay pricing unless the strategic benefit of delay is large enough and allows a comparative static analysis where, depending on the cost of delay, many patterns of price leadership may emerge).

\footnotetext{
${ }^{2}$ This is a technical assumption ensuring that the price leadership structure is not simply an artefact of the network structure and the absence of connections between specific sellers.

${ }^{3}$ In other words, we do not consider any form of simultaneous pricing game, which usually does not have a pure strategy equilibrium. Characterizing mixed strategy equilibria in the presence of price leaders and followers would be an interesting theoretical exercise, but we do not pursue it here.

${ }^{4}$ The cost of delay could be a complex function of many factors including the (im)patience of the managerial board members and the stock holders, the decision rule aggregating their time preferences, the interest rate, the financial structure of the firm, the demand elasticity of each product, consumers' shopping cost, and the contracts and payment terms with the producers/suppliers.
} 


\subsection{Outcomes}

Given this set-up, who would be the leader(s) and who would be the follower(s)? First note that in sequential pricing games there exists a second-mover (or a late-mover) advantage. In duopoly ( $n=$ 2), as Deneckere et al. (1992) establish, the one with more loyal consumers leads the other. This is because other things being equal, the opportunity cost of price-cutting to win the switchers is proportional to the number of loyal consumers, and because the one with the lower opportunity cost takes the switchers in any sequential pricing game. Thus, the one with the more loyal consumers has no reason to delay setting its price, i.e., ends up being the price leader. More specifically, the minimum price that seller $i$ is willing to set, $p_{i}$, is characterized by:

$$
\underline{p_{i}} \cdot\left(L_{i}+S_{i}\right)=r \cdot L_{i}
$$

Note that $\underline{p}_{2}<\underline{p}_{1}$ if and only if $L_{2}<L_{1}$, since $S_{1}=S_{2}$ in duopoly. In other words, the seller with the smaller loyal consumer group has a smaller opportunity cost of price-cutting, and thus is in a more advantageous position in competitive terms. Moreover, $\underline{p}_{2}<\underline{p}_{1}$ implies that seller 2 will win the switchers even if she becomes the price leader and that seller 1's payoff will always be $r \cdot L_{1}$. Since the seller with the larger loyal consumer group cannot improve her profit by delaying setting her price, she may therefore be willing to take the role of Stackelberg leader.

Building on the insight of Deneckere et al. (1992) that the opportunity cost of price-cutting is proportional to the size of the loyal consumer group, so that sellers who are less reliant on loyal consumers will be more prepared to delay setting their prices, we can establish the following proposition on the resulting character of price leadership in $n$-seller oligopoly:

Proposition. If the cost of delay $\varepsilon$ is sufficiently small then there exists an equilibrium in which seller $i$ makes a commitment to the $i$-th opportunity to be the $i$-th mover. If, though, $\varepsilon$ is large enough then all sellers compete to set price as early as possible.

Proof. See the appendix.

The proposition shows that the price leadership structure depends on the size of the cost of delay. As long as $\varepsilon$ is low then sellers with low LS ratios will be prepared to wait for others to set their price first, with the intent to fractionally undercut them to grab the switchers. Conversely, sellers with high LS ratios have less incentive to delay their pricing because lowering their price entails reduced revenue 
from their loyal customers and they will not be able to win switchers anyway, so they might as well set price early and save on the cost of delay. The outcome is an ordered price leadership sequence from seller 1 to seller $n$. However, if instead the cost of delay is high then there is a scramble amongst sellers to set price as early as possible, resulting in a random order.

What happens when the cost of delay is in the intermediate range? The general model does not make this clear. Accordingly, it is worth exploring this further with an example to gain some insight.

\subsection{Triopoly example}

Consider a market with three sellers, $\mathrm{X}, \mathrm{Y}$, and Z, as illustrated in Figure 1. Seller $\mathrm{X}$ has a loyal consumer group of mass 5 (5 loyal consumers for short), and shares 1 switcher with each of sellers $Y$ and Z. Seller $Y$ has 4 loyal consumers, and shares 1 and $S_{Y Z}$ switchers with sellers $X$ and $Z$, respectively. Seller $Z$ has 3 loyal consumers. Sellers $X, Y, Z^{\prime}$ 's LS ratios are $5 / 2,4 /\left(1+S_{Y Z}\right)$ and $3 /\left(1+S_{Y Z}\right)$, respectively. Assume that $S_{Y Z}>3 / 5$ so that seller $Z$ has the smallest, and $Y$ the second smallest LS ratios. Furthermore, to meet the requirement of A6, assume that $S_{Y Z}<3$.

\section{- Figure 1 near here -}

Since seller Z's LS ratio is the smallest among the three, $Z$ is to be a price follower in this triopoly. In particular, if the cost of delay $\varepsilon$ is sufficiently small, $X$ will price first, $Y$ second, and $Z$ lastly. In equilibrium, all sellers set the maximum price $\left(p_{X}=p_{Y}=p_{Z}=r\right)$. The individual profits are $\pi_{X}=5 r$, $\pi_{Y}=5 r-\varepsilon$, and $\pi_{Z}=\left(4+S_{Y Z}\right) r-2 \varepsilon$. To check whether this is indeed an equilibrium, it suffices to examine $X$ 's incentive to deviate, because the later movers (i.e., sellers $Y$ and $Z$ ) obviously do not want to be the first mover (which may not be the case if $\varepsilon$ is large), and seller Y's incentive is very similar to that of the leader in a duopoly. Suppose that seller $X$ considers to choose the second slot and to become the second mover, which makes seller $Y$ the first mover. Since $S_{Y Z}$ and $S_{Z X}$ will be taken by seller $Z$ anyway, the game between $X$ and $Y$ boils down to a model of duopoly. Suppose $X$ became the second mover and $\mathrm{Y}$ became the first. If $\mathrm{Y}$ accommodates $\mathrm{X}$ 's deviation (i.e., gives up $S_{X Y}$ ), her profit will drop to $4 r$, but if she fights back by lowering the price to $p_{Y}=5 r / 6$, her profits will be $25 r / 6(>4 r)$, in which case seller $\mathrm{X}^{\prime}$ s profit will be $5 r-\varepsilon$. Therefore, $\mathrm{X}$ will not try to be the second mover. 
Now suppose that $X$ chose the third slot to become the third mover, $Y$ being the first and $Z$ being the second. Although sellers $Y$ and $Z$ are disadvantaged by the timing of moves, they still can keep their switchers by lowering the prices to $p_{Y}=5 r / 6$ and $p_{Z}=5 r / 7$. Notice that given $p_{Y}=5 r / 6$, seller $Z$ has no incentive to accommodate seller $X$ by increasing her price to $5 r / 6$. More precisely, as long as $S_{Y Z}<3$ (as A6 requires), the following inequality holds:

$$
\frac{5}{7} r \cdot\left(4+S_{Y Z}\right)>\frac{5}{6} r \cdot\left(3+S_{Y Z}\right)
$$

where the left-hand-side of the inequality is the profit when not accommodating $\mathrm{X}$ and the right-handside is the profit when accommodating $X$. In other words, seller $X$ fails to win the switchers even when she becomes the third mover, and thus has no reason to try to be the third mover.

In this equilibrium, $Y$ plays both roles of leader and follower, and $X$ price-leads $Z$ indirectly through Y. Note that even if there are consumers who may visit all three sellers, the order of pricing is not affected, because the relative competitive advantages of the sellers are not affected by them. If the cost of delay $\varepsilon$ is large enough, on the other hand, everybody will try to price first, and consequently the order will be randomly determined. Thus, there will be no clear price leadership.

What then happens if $\varepsilon$ is in the intermediate range? Depending on the size of $S_{Y Z}$, both $\mathrm{X}$ and $\mathrm{Y}$ may try to be the price leader, while $\mathrm{Z}$ prices later. Alternatively, $\mathrm{X}$ becomes the only price leader, while $\mathrm{Y}$ and $\mathrm{Z}$ try to be the second mover. Suppose that there are sufficiently many switchers between $Y$ and $Z$, more precisely, $S_{Y Z}$ is greater than $5 / 6$. In this case, seller $Z$ would want to wait for $Y$ to move first as long as the cost of delay is not very large. In contrast, seller Y may want to be the leader if the cost of delay is not negligible, precisely, if $\varepsilon>5 r / 12$. Recall that even if $\mathrm{Y}$ becomes the first mover (while $X$ becomes the second, and $Z$ the last), the switchers between $X$ and $Y$ are served by seller $Y$, because $Y$ lowers her price to $p_{Y}=5 r / 6$ which is too low for $X$ to match. In this case, the profit of $Y$ is $25 r / 6$, and thus the profit loss of $Y$ due to being the price leader is $5 r / 6(=5 r-25 r / 6)$. This loss is realized only when $\mathrm{Y}$ becomes the first mover, which occurs with probability $1 / 2$, given that both $\mathrm{X}$ and $Y$ choose the first slot. To sum up, if the cost of delay is greater than the expected profit loss, $5 r / 12$, both sellers $X$ and $Y$ choose the first slot to be the first mover.

Alternatively, if there are only a few switchers between $Y$ and $Z\left(S_{Y Z}<5 / 6\right)$, seller $Z$ may want to focus on the interaction with seller $\mathrm{X}$, neglecting the interaction with $\mathrm{Y}$. In particular, if the cost of 
delay is greater than $S_{Y Z} / 2$, seller $Z$ chooses the second slot. Also, if $Z$ becomes the second mover (while $\mathrm{X}$ becomes the first, and $\mathrm{Y}$ the third), seller $\mathrm{Z}$ will lower her price to $p_{Z}=4 r /\left(4+S_{Y Z}\right)$, which is low enough to prevent the switchers from being served by seller $Y$. Notice that this price approaches the reservation price $r$ as $S_{Y Z}$ decreases, meaning that sellers $Y$ and $Z$ do not compete intensively over the switchers if $S_{Y Z}$ is small. In such a case, seller $Z$ is likely to choose the second slot, because defending the switchers from $Y$ is relatively easy.

In sum, when the cost of delay $\varepsilon$ is small enough, $\mathrm{X}$ becomes the first mover, $\mathrm{Y}$ the second, and $\mathrm{Z}$ the last. In contrast, when $\varepsilon$ is large enough, there is neither a leader nor a follower. When $\varepsilon$ is in the intermediate range, either of the following happens: (i) both $X$ and $Y$ try to be the leader, and $Z$ follows; or (ii) $\mathrm{X}$ price-leads the others, and there is no clear leader-follower relationship between $\mathrm{Y}$ and $\mathrm{Z}$. Furthermore, the expected prices and profits are highest when there is a clear industry-wide leaderfollower relationship (that is, when $\varepsilon$ is small), which suggests that price leadership can help increase the prices without an attempt to collude.

We appreciate this is just an example and that the results are sensitive to the cost of delay, but nonetheless there are insights that might have relevance to empirical predictions. In particular, we hypothesize that the sequence of firms in price setting could relate to the size order of LS ratios and the extent to which pairs of firms share switcher consumers in the following two ways:

Hypothesis 1. Firms with higher LS ratios are likely to price-lead those with lower LS ratios.

Hypothesis 2. Pairs of firms that share many customers are likely to be in a leader-follower relationship, especially when their LS ratios differ.

\section{Empirical Method}

\subsection{Definition}

In this section, we first review the pairwise test proposed by SW, explaining why a spurious relationship problem can arise with their approach when going beyond two firms, but then show how this can be resolved with our $n$-firm oligopoly method. The definition of price leadership put forward by SW is as follows: 'price leadership occurs when one firm makes a change in a price (or set of prices) that is followed within a predetermined short period by the other (more generally, another) firm 
making a price change of exactly the same monetary amount in the same direction on the same product(s), and doing so significantly more often than would be expected by chance' (p. 392).

To operationalize this definition, SW restrict their focus to two firms (in their exercise, Asda and Tesco) and fix the response time to 1 or 2 weeks. Then, they count leadership incidences and simultaneous price changes of the same amounts on the same products. The test is to check whether the leadership incidences are significantly more frequent than the simultaneous price changes.

When there are more than two (non-negligible) firms in the market, there are a few conceptual and practical complications which do not exist in duopoly. First, the price leader or the follower in the market may not exist at all. Instead, some price leaders may also be followers at the same time, so leader-follower relationships must be defined within pairs or subgroups of firms. Second, there may exist different types of leaderships such as joint leaderships or indirect leaderships. Joint leadership indicates the following situation: two or more firms (none of which alone is a price leader) may together lead another firm. Indirect leadership may take the form where $X$ does not price-lead $Z$ directly, but if $X$ leads $Y$ and $Y$ leads $Z$, then $X$ may be able to indirectly influence $Z$ via $Y$. In this case, we can say that $\mathrm{X}$ has an indirect leadership over $\mathrm{Z}$ via $\mathrm{Y}$. In principle, the chain of influence can be as long as the number of firms in the market.

On a more practical side, the pairwise test proposed by SW may produce misleading results. For instance, even if $X$ alone does not price-lead $Y$, it may appear so if $X$ and one or more other firms are jointly price-leading $\mathrm{Y}$. Alternatively, even if $\mathrm{X}$ itself does not lead $\mathrm{Y}$ in any sense, $\mathrm{X}$ may still appear to lead $\mathrm{Y}$ because $\mathrm{X}$ changed its prices for sufficiently many times simultaneously with another firm which

price-leads Y. In other words, the pairwise test may identify spurious leadership when there are more than two firms. Thus, we propose a refinement procedure to rule out such leaderships and to make a clearer case of single-handed leaderships. While doing so, we will be able to identify joint or indirect leaderships if any exist.

\subsection{Generalized Seaton-Waterson (GSW) method}

Our procedure involves the following five steps:

(i) We start with the pairwise tests. Denote a change in a price of retailer $X$ at week $t$ by $X(t)$ and let $Y(t+1)$ be a price change of the same amount by retailer $Y$ in the next week or the week after the 
next week (that is, within two weeks). The relevant events are then: $\{X(t), Y(t)\},\{X(t), Y(t+1)\},\{Y(t)$, $X(t+1)\}$. Expressed in words, the three relevant events are ' $X$ and $Y$ simultaneously changed a price (of the same product by the same amount)', 'X price-led $Y$ ' or ' $Y$ price-led $X$ '. When the events in the second category are significantly more frequent than the first type of events, we say ' $\mathrm{X}$ priceleads Y.' On the other hand, if the third type of events are more frequent compared to the first events, it is said that ' $Y$ price-leads $X^{\prime} .^{5}$ For each pair $(X, Y)$, we test both $X^{\prime}$ 's and $Y^{\prime}$ 's leadership by comparing the numbers of incidences of $\{X(t), Y(t+1)\}$ and $\{Y(t), X(t+1)\}$ to that of $\{X(t), Y(t)\}$. If for all price followers designated $Y$ it is the case that $Y$ is led only by $X$, i.e. if each follower has a single leader, then the identification procedure stops, and we conclude: the leaderships identified by the pairwise tests are genuine, single-handed leaderships, and there does not exist a joint leadership.

(ii) If a follower firm, say $Z$, turns out to be led by more than one leader firm, say $X$ and $Y$, then we conduct 3-group-wise test for each group of two leader firms and one follower firm. To test X's single-handed leadership, we test whether the incidences of $\{X(t), Y(N), Z(t+1)\}$ or $\{X(t), Y(t+1), Z(t+1)\}$ are sufficiently more frequently observed than those of $\{X(t), Y(t), Z(t+1)\}$ where $\mathrm{Y}(\mathrm{N})$ indicates that the price of firm $\mathrm{Y}$ has not changed at all or changed by a different amount during the period of interest. If $X$ passes the 3-group-wise tests with all the other leaders of $Z$, then X's leadership is confirmed. Otherwise, we regard X's leadership over Z as a spurious one. The refinement procedure for single-handed leaderships stops here.

(iii) If in the 3-group-wise test, the incidences of $\{X(t), Y(t), Z(t+1)\}$ turns out to be sufficiently more frequent than both those of $\{X(t), Y(N), Z(t+1)\}$ or $\{X(t), Y(t+1), Z(t+1)\}$ and those of $\{Y(t), X(N), Z(t+1)\}$ or $\{\mathrm{Y}(t), \mathrm{X}(t+1), \mathrm{Z}(t+1)\}$, that is, if neither $\mathrm{X}$ nor $\mathrm{Y}$ holds a single-handed leadership and the joint leadership incidences are significantly more frequent, we say that there may exist a joint leadership of $\mathrm{X}$ and $\mathrm{Y}$ over $\mathrm{Z}$. If there is no other firm which price-leads $Z$, then the joint leadership is confirmed, and the procedure stops.

\footnotetext{
${ }^{5}$ In principle, $X$ 's leadership over $Y$ and Y's leadership over $X$ can co-exist. However, neither SW nor we found such an incidence in our respective grocery price data.
} 
(iv) If there is a firm other than $X$ and $Y$ which price-leads $Z$, then we repeat the refinement procedure. In 4-group-wise test involving $X, Y, Z$ and another leader $A$, we compare $\{X(t), Y(t), A(t), Z(t+1)\}$ to $\{X(t), Y(t), A(N), Z(t+1)\}$ and $\{X(t), Y(t), A(t+1), Z(t+1)\}$. Depending on the test result, we either confirm the joint leadership of $X$ and $Y$ or move on to testing the joint leadership of $X, Y$ and $A$. The procedure stops if there is no more possible cases of joint leadership or if the number of relevant observations for the test is not large enough to give any conclusion. Otherwise, we keep examining joint leaderships of $n$ firms by $(n+1)$-group-wise tests.

(v) If according to the pairwise test results, $X$ leads $Y$ and $Y$ leads $Z$, we further test $X$ 's indirect leadership over $Z$ by modifying the time lag from 1 or 2 weeks to 3 or 4 weeks. While doing so, we keep the other requirements (that is, of the same amount on the same product) fixed. If there exists a longer chain of leader-follower relationships, we also test those indirect leaderships by adjusting the response time accordingly.

Note that we generalize the identification strategy of SW to eliminate spurious leadership cases and to identify joint and indirect leaderships. Our method is conservative, so helps to focus on the clearest cases. To illustrate how the procedure can be applied in practice, we use a dataset of fresh produce prices for a long time span to examine the leadership structure amongst British supermarkets.

\section{British supermarket competition}

\subsection{Context}

Food retailing in Britain is one of the most concentrated and differentiated retail grocery markets in Europe. Our empirical analysis focuses on the leading seven mainstream supermarket retailers, which over our period of study, 2007-2013, together controlled around $90 \%$ of supermarket sales in the UK. These consist of the so-called 'Big 4' retailers - Tesco (T), Sainsbury (S), Asda (A) and Morrisons (M) - operating predominantly from large-format superstores, along with M\&S (MS) and Waitrose (W) as upmarket retailers focusing on higher income consumers, and Co-operative Food (CF) as a convenience retailer focusing on neighbourhood retailing. ${ }^{6}$

\footnotetext{
6 We do not have sufficient data to include hard discount retailers in our study. In our timeframe, the two leading hard discount retailers, Aldi and Lidl, each had less than 3\% national share. However, both retailers have grown rapidly in the last few years, so they are now a much more important feature in the sector (CMA 2019).
} 
Even amongst the Big 4 perceived differentiation arises in respect of product ranges, services and consumer appeal. Sainsbury is seen as more upmarket than the others, while Asda (under Walmart's ownership) is more price focused as an 'everyday low price' ('EDLP') positioned retailer, with Morrisons value-oriented and Tesco has taken the middle ground as the retailer having the broadest appeal and holding the highest market share. ${ }^{7}$ Nevertheless, they are competing for the bulk of British consumers, where they account for three-quarters of supermarket sales in Britain. The other retailers are smaller but still serve consumers right across the demographic range and with national coverage. Accordingly, these retailers should be directly competing with each other, which should be evident in perhaps the most staple product category of all represented by fresh fruit and vegetables.

\subsection{Price data}

Our supermarket retail price dataset is the same as that used by Lan and Dobson (2017), sourced from the trade magazine Horticulture Week ('HW') covering weekly updated prices on a selection of 26 fruits and vegetables from the leading seven UK supermarket retailers for the period October 2007 to April 2013 (288 weeks). The retailers use national uniform pricing across their store networks for their larger supermarket store formats, making price data collection and comparison more straightforward than in many other countries where local pricing predominates (Dobson and Waterson 2005; Chakraborty et al. 2015). While the number of products in our data is considerably smaller than the 370 considered in SW, these are matched items across the seven retailers so overall this HW retail price dataset provides a panel of 52,416 weekly prices. The online appendix contains summary details of the dataset, which shows that the Big 4 retailers tend to have lower average prices than the other three retailers, but there is a mix on the rank order and prices are typically dispersed.

In respect of price changes, we are able to distinguish between regular prices and temporary price reductions (TPRs) by taking account of the magnitude of price changes. We define a TPR using Algorithm B proposed by Nakamura and Steinsson (2008). Specifically, we use a 10\% or more price drop that occurred for one to six weeks before reverting back to the previous price as a typical TPR in the dataset. This definition is also consistent with the application of SW. Then, the regular prices can

\footnotetext{
${ }^{7}$ At the time of writing, the UK's competition authority is investigating a proposed merger between Sainsbury's and Asda - https://www.gov.uk/cma-cases/j-sainsbury-plc-asda-group-ltd-merger-inquiry.
} 
be filtered out from original prices by removing TPRs. We focus our empirical analysis on testing leadership using regular prices for a direct comparison to SW. ${ }^{8}$ For our product sample, we identified 2,460 increases and 2,133 decreases in regular prices, of which we found respectively 501 and 373 identical price rises and falls to be leadership-relevant price changes, i.e. $18.6 \%$ of price changes were exactly matching and sequentially started within two weeks.

\subsection{Predictions based on LS ratios}

Our theoretical model stresses the importance of the relative sizes of each firm's loyal customer base in predicting the sequence of pricing moves. While our HW price dataset does not contain any information on consumer purchasing behaviour, we separately have consumer panel information from Kantar Worldpanel, as used by Nakamara et al. (2015), on where consumers undertake their main grocery shopping for the 52 weeks of 2010. This is midway in our sample period and we treat this as representative of shopping patterns for our timeframe where retailer positions were broadly stable. ${ }^{9}$ For that year, we find that over three-quarters of surveyed households made frequent use of either just one or two of the seven mainstream retailers for their regular large supermarket shopping trips. By designating those households shopping at one retailer as 'loyal' consumers and those shopping at two retailers as 'switcher' consumers, we can construct loyal/switcher 'LS' ratios using the information shown in Table $1 .{ }^{10}$

\section{- Table 1 near here -}

Each column shows the composition of consumer groups of each retailer, so the numbers in each column add up to one. The leading diagonal elements are the proportion of loyal consumers, and the off-diagonal elements are the proportions of switchers. For instance, the number in cell $(2,1)$ is the proportion of switchers who visited Tesco and Asda among Tesco customers. The number in cell $(1,2)$ is also the proportion of the same switchers, but the number is smaller $(0.179<0.186)$ because the

\footnotetext{
${ }^{8}$ For the interested reader, we provide the results on TPR leadership in the online appendix.

9 The online appendix provides extensive details on comparisons across the years around 2010 to show retailers' relative positions were quite stable in respect of sales performance, market shares, customer demographic profiles, household penetration rates, and customer loyalty rates for retailer main shoppers.

${ }^{10}$ The online appendix provides further details of the Kantar Worldpanel data and households' retailer choices.
} 
number of Asda customers is larger than that of Tesco customers in this sample. The largest switcher groups for each retailer are marked grey. For instance, Asda is the largest rival for Tesco, whereas Morrisons is for Asda, and Tesco is for Sainsbury. In addition, as a rough guide, we have included an 'indicative LS ratio', shown in italics, which is the leading diagonal value (representing loyal shoppers) divided by its complement, one minus the leading diagonal value (representing switchers).

While the indicative LS ratio might be a guide, the actual procedure required, following the logic of the model with a low cost of delay, is to look at identifying the sequence in reverse order through eliminating the switchers at the subsequent mover. Since M\&S has the lowest LS ratio, M\&S would set its prices lastly. Once we eliminate the switchers who visit M\&S, Co-op has the lowest LS ratio. By repeatedly eliminating the next follower, we end up with the following sequence: Asda, Tesco, Morrisons, Sainsbury, Waitrose, Co-op, and M\&S. ${ }^{11}$ In this case, we may detect a long chain of indirect leaderships. In contrast, if the cost of delay is large enough then no retailer would wait for other firms to set their prices, and thus we would not expect to find any clear price leadership pattern.

However, if the cost of delay were in the intermediate range then it is conceivable that there might be no clear leader-follower relationship between similar firms but there could be between dissimilar firms. Thus, it is possible that we could find cluster hierarchies, where firms in each cluster have similar LS ratios, and then leader-follower patterns to exist between pairs of firms at successive hierarchical levels based on the extent to which they share each other's customers. Specifically, drawing on Hypotheses 1 and 2, we may speculate that, since both Tesco and Asda (which are similar in terms of their LS ratios) share a great number of consumers with Sainsbury and Morrisons (which are similar in terms of their LS ratios), Tesco and Asda might jointly lead Sainsbury and Morrisons. If not, Tesco could be the leader of Sainsbury, and Asda lead Morrisons, because Tesco is Sainsbury's largest rival, and Asda is Morrisons (see the grey cells). By a similar logic, M\&S and Waitrose would likely follow Sainsbury.

${ }^{11}$ The online appendix A2 provides full details. 


\section{Identifying the leadership structure amongst British supermarkets}

\subsection{Pairwise test of leadership}

We first examine the price leadership between pairs of retailers using the test proposed by SW to see what simple but potentially misleading pairwise results emerge. Following SW, we explore the price-up and the price-down cases separately. For inference, we use exact binomial probability tests rather than the approximation tests using the normal distribution which SW used in their paper. ${ }^{12}$ The pairwise test results for all 21 pairs of retailers are shown in Table 2 and the statistically significant relationships are then represented in Figure 2 respectively for price rises (on the left) and price falls (on the right).

\section{- Table 2 and Figure 2 near here -}

An arrow from $X$ to $Y$ in Figure 2 represents the leadership of $X$ over $Y$. In other words, the arrow indicates that leadership incidences $\{X(t), Y(t+1)\}$ are observed as statistically significant (at 95\% level) more often than the simultaneous price-change incidences $\{X(t), Y(t)\}$. The panel on the left shows the price rise ('upward') leaderships and the panel on the right shows the price cut ('downward') leaderships. In both panels, one can clearly see that there is a three-tier structure in this industry. Among the 'Big 4', two retailers, i.e. Tesco and Asda, turn out to lead the other two, i.e. Sainsbury and Morrisons. Yet, these latter two are also leaders with respect to non-Big 4 retailers, i.e. M\&S, Waitrose and Co-operative Food. Accordingly, we can group them into three: the 'leaders' (Asda and Tesco), the 'first followers' (Sainsbury and Morrisons) or the 'second followers' (Marks \& Spencer, Waitrose and Co-operative Food). This three-tier structure is strictly hierarchical in the sense that no firm in the leader group follows a firm in the follower groups. Also, neither is it the case that a firm in the first follower group is led by a firm in the second follower group.

As shown in the left panel, Tesco appears to have an upward price leadership over all the other retailers except Asda. In other words, when Tesco increases the price of a product, most of the other retailers tend to increase the price of the same product by the same amount within two weeks. In contrast, when Tesco lowers a price of a product, Morrisons and Co-operative Food tend not to follow

\footnotetext{
${ }^{12}$ As the statistical theory suggests, if we had large sample size, it would not matter which test was used, but binomial probability test is preferred with a small sample size like ours.
} 
Tesco's lead (see the right panel). However, Morrisons appears to exercise upward leaderships over those in the second follower group. Though, similar to Tesco's position, none of the second followers are led by Morrisons' price cuts. The asymmetry between the upward and downward leaderships suggests more coordination with price increases than with price cuts and different roles between Tesco (being especially influential in leading price increases) and Asda (which is more influential in leading price cuts than price rises).

\subsection{Refinement}

As discussed, the risk with pairwise tests is that they may identify spurious leaderships. In particular, from Figure 2, we observe that Sainsbury, M\&S, Waitrose and Co-operative Food are led by more than one firm, so potentially, some of those leaderships may not be genuinely single-handed.

To focus on clearer cases of price leadership, we use 3-group-wise tests which involve two leader firms and one follower firm. For instance, according to the pairwise test results, Sainsbury is led by two firms, Tesco and Asda. In this case, it is ambiguous whether each of Tesco and Asda leads Sainsbury single-handedly or they somehow jointly lead the follower. It is also possible that both firms' leaderships are spurious. To examine statistically whether Tesco's leadership is genuine, we compare the number of incidences that Tesco price-led Sainsbury without a help of Asda to the number of incidences that Tesco and Asda jointly led Sainsbury. The results of this 3-group-wise test are reported in Table 3. When Tesco passes this test, the price leadership of Tesco is confirmed. However, if it does not pass a test with another leader, the leadership is regarded as spurious. The thick arrows in Figure 3 show the confirmed leaderships.

\section{- Table 3 and Figure 3 near here -}

In comparison with the pairwise test results, Tesco's leadership over M\&S (for both upward and downward cases), Asda's leadership over Waitrose (for upward case), Morrisons' leadership over M\&S (for upward case) and Tesco's leadership over Waitrose (for downward case) turn out to be spurious according to our criterion. However, many of the leader-follower relationships identified in the pairwise test, for instance Tesco's upward leadership over Sainsbury, Morrisons, Waitrose, and Cooperative Food, are further corroborated. In total, 7 upward and 5 downward leaderships are confirmed. 
The three-tier structure that we observed in the original pairwise test results is still apparent in the refined picture. Tesco tends to lead on price rises, and leaderships are less prevalent in price cut cases. The first followers, Sainsbury and Morrisons, indeed appear to play both roles of leader and follower. One can also see that especially when the retailers cut their prices, Tesco has a greater influence over those targeting higher-end consumers, Sainsbury, M\&S and Waitrose, while Asda's prices influence Morrisons, which arguably appeals to more value-oriented customers.

\subsection{Joint and indirect leaderships}

When the incidences of simultaneous price changes are sufficiently more frequent in a 3-groupwise test, we test further to confirm the presence of joint leadership. However, as shown in Table 3, in our sample, there are no such cases. Thus, we conclude that there is no identifiable joint leader in the industry, and we do not explore this aspect further in the context of this application.

Nevertheless, there are quite a few potential indirect leadership cases. For instance, Tesco priceleads Sainsbury, and Sainsbury leads M\&S both upward and downward. Therefore, Tesco may indirectly lead M\&S. Similarly, Tesco may indirectly price lead Waitrose and Co-operative Food via Morrisons, and Asda may indirectly lead M\&S via Sainsbury. For upward leadership, Tesco may indirectly lead M\&S and Waitrose. We test these potential indirect leaderships by modifying the response time from 1-2 weeks to 3-4 weeks. The results are reported in Table 4, showing that out of the seven potential indirect leadership cases there are two that appear to be confirmed, with both involving Tesco: Tesco indirectly leads M\&S and Waitrose downward.

- Table 4 near here -

\subsection{Robustness checks}

We apply two forms of robustness checks. Firstly, while the SW method uses only identical price changes, we also examine patterns based on similar or proportionate price changes. We find some differences in the strength of the relationships but they remain qualitatively the same with those reported above. Secondly, we apply vector autoregression (VAR) analysis in both price differences and price levels to explore Granger-causal relationships, finding support for the same three-tier structure in which the prices of firms in a higher tier tend to Granger-cause the prices of those in a lower tier. 


\section{Conclusion}

This paper provides a means for identifying price leadership structures in $n$-firm oligopoly and a theoretical explanation for how hierarchical structures could emerge with firms taking on dual roles in leading and following different groups. As an application, our examination of price leadership amongst UK supermarkets reveals a three-tier structure where Tesco and Asda tend to price-lead the other retailers, while Sainsbury and Morrisons play both roles of leader and follower. These results lend support to our two hypotheses that firms with higher LS ratios are likely to price-lead those with lower LS ratios and that pairs of firms that share many customers are likely to be in a leader-follower relationship, especially when their LS ratios differ. Based on our theoretical model, the results correspond to the cost of delay in the intermediate range.

As markets evolve then leadership patterns may change over time. The Competition and Markets Authority blocked the recent proposed merger between Asda and Sainsbury's on the grounds that it would lessen competition and raise prices in the UK (CMA 2019). If the merger had proceeded then it could well have changed our identified three-tier price leadership structure in creating a new market leader and a dominant duopoly with Tesco. The other major development since our data series finished in 2013 has been the rapid expansion of Aldi and Lidl, as hard discounters, who might now be taking price leadership positions at a time when shopper loyalty appears to be declining (CMA 2019). Shopper promiscuity in using a variety of stores, rather than just one or two, limits the extent to which our model is applicable, when it is unclear which potential switcher customers a retailer might target. Even so, our empirical method remains valid and offers a means to monitor changes in price leadership patterns in such evolving markets.

\section{Supplementary material}

Supplementary material is available online at the OUP website. This comprises an online appendix providing full details of all tests and different robustness checks along with extensive background information on the grocery market and shopper behaviour in the UK relating to the study period.

\section{Acknowledgements}

We are extremely grateful for the helpful comments from three anonymous reviewers and the editor, James Forder. All authors contributed equally to the paper. 


\section{References}

Amir, R. and Stepanova, A. (2006) Second-mover advantage and price leadership in Bertrand duopoly, Games and Economic Behavior, 55, 1-20.

Andreoli-Versbach, P. and Franck, J.-U. (2015) Endogenous price commitment, sticky and leadership pricing: evidence from the Italian petrol market, International Journal of Industrial Organization, 40, 32-48.

Burdett, K. and Judd, K. (1983) Equilibrium price dispersion, Econometrica, 51, 955-69.

Chakraborty, R., Dobson, P.W., Seaton, J.S., and Waterson, M. (2014) Market consolidation and pricing developments in grocery retailing: a case study. In: Pietz M., Spiegel,Y. (Eds.), Analysis of Competition Policy and Sectoral Regulation, World Scientific, Singapore, 3-29.

Chakraborty, R., Dobson, P.W., Seaton, J.S., and Waterson, M. (2015) Pricing in inflationary times: the penny drops, Journal of Monetary Economics, 76, 71-86.

CMA (2015) Pricing practices in the groceries market: Response to a super-complaint made by Which? on 21 April 2015, Competition and Markets Authority, London, https://assets.digital.cabinetoffice.gov.uk/media/55a6c83540f0b61562000005/Groceries_Pricing_Super-

Complaint_response.pdf (accessed 9 August 2019).

CMA (2019) Anticipated merger between J Sainsbury PLC and Asda Group Ltd: Final report, Competition and Markets Authority, London, https://assets.publishing.service.gov.uk/media/5cc1ec1340f0b64031cfa6f0/Final_reportSA.pdf (accessed 9 August 2019).

Competition Commission (2000) Supermarkets: a report on the supply of groceries from multiple stores in the United Kingdom, Cm 4842, TSO, London.

Competition Commission (2003) Safeway plc and Asda Group Limited (owned by Wal-Mart Stores Inc); Wm Morrison Supermarkets plc; J Sainsbury plc; and Tesco plc: A report on the mergers in contemplation, TSO, London.

Competition Commission (2008) The supply of groceries in the UK, TSO, London.

Deneckere, R. and Kovenock, D. (1992) Price leadership, Review of Economic Studies, 59, 143-62.

Deneckere, R., Kovenock, D., and Lee, R. (1992) A model of price leadership based on consumer loyalty, Journal of Industrial Economics, 40, 147-56.

Dobson, P.W. and Waterson, M. (2005) Chain-store pricing across local markets, Journal of Economics and Management Strategy, 14, 93-119.

Forchheimer, K. (1908) Theoretisches zum unvollstandigen monopol, Schmollers Jahrbuch fur Gesetzgebund, Verwaltung und Volkswirtschaft, 32, 1-12.

Furth, D. and Kovenock, D. (1993) Price leadership in a duopoly with capacity constraints and product differentiation, Journal of Economics, 57, 1-35.

Gilpatric, S. and Li, Y. (2016) Endogenous price leadership and the strategic acquisition of information, Southern Economic Journal, 82, 859-73.

Güth, W., Pull, K., Stadler, M., and Zaby, A. (2014) Endogenous price leadership: a theoretical and experimental analysis, Journal of Economic Behavior and Organization, 108, 420-32.

Hamilton, J. and Slutsky, S. (1990) Endogenous timing in duopoly games: Stackelberg or Cournot equilibria, Games and Economic Behavior, 2, 29-46. 
Hirata, D. and Matsumura, T. (2011) Price leadership in a homogeneous product market, Journal of Economics, 104, 199-217.

Lan, H. and Dobson, P.W. (2017) Healthy competition to support healthy eating? An investigation of fruit and vegetable pricing in UK supermarkets, Journal of Agricultural Economics, 68, 881-900.

Lewis, M. (2012) Price leadership and coordination in retail gasoline markets with price cycles, International Journal of Industrial Organization, 30, 342-351.

Li, Y. (2014) Price leadership in a vertically differentiated market, Economic Modelling, 38, 67-70.

Lloyd, T. (2008) Price leadership in UK food retailing: time series representation and evidence, 82nd Annual Conference of the Agricultural Economics Society, Cirencester, UK.

Mouraviev, I. and Rey, P. (2011) Collusion and leadership, International Journal of Industrial Organization, 29, 705-17.

Nakamura, E. and Steinsson, J. (2008) Five facts about prices: a reevaluation of menu cost models, Quarterly Journal of Economics, 123, 1415-64.

Nakamura, R., Suhrcke, M., Jebb, S., Pechey, R., Almiron-Roig, E., and Marteau, T. (2015) Price promotions on healthier compared with less healthy foods: a hierarchical regression analysis of the impact on sales and social patterning of responses to promotions in Great Britain, American Journal of Clinical Nutrition, 101, 808-16.

Ono, Y. (1982) Price leadership: a theoretical analysis, Economica, 49, 11-20.

Pastine, I. and Pastine, T. (2004) Cost of delay and endogenous price leadership, International Journal of Industrial Organization, 22, 135-45.

Revoredo-Giha, C. and Renwick, R. (2012) Retailers price behavior in the UK fresh fruit and vegetable market, Agribusiness, 28, 451-68.

Rotemberg, J. and Saloner, G. (1990) Collusive price leadership, Journal of Industrial Economics, 39, 93-111.

Saving, T.R. (1970) Concentration ratios and the degree of monopoly, International Economic Review, $11,139-46$.

Seaton, J.S. and Waterson, M. (2013) Identifying and characterising price leadership in British supermarkets, International Journal of Industrial Organization, 31, 392-403.

Tasnádi, A. (2004) On Forchheimer's model of dominant firm price leadership, Economics Letters, 84, 275-9.

Tasnádi, A. (2016) Endogenous timing of moves in Bertrand-Edgeworth triopolies, International Journal of Economic Theory, 12, 317-334.

Thomassen, $\varnothing$., Smith, H., Seiler, S., and Schiraldi, P. (2017) Multicategory competition and market power: a model of supermarket pricing, American Economic Review, 107, 2308-51.

van Damme, E. and Hurkens, S. (2004) Endogenous price leadership, Games and Economic Behavior, 47, 404-20.

von Stackelberg, H. (1934) Marktform und Gleichgewicht, Springer, Wien.

Wang, Z. (2009) (Mixed) Strategy in oligopoly pricing: evidence from gasoline price cycles before and under a timing regulation, Journal of Political Economy, 117, 987-1030. 


\section{APPENDIX - PROOF OF PROPOSITION}

Let us first define the demand for seller $i$ 's product when seller $i$ wins $(j-1)$ groups of switchers as

$$
Q_{i}(j) \equiv L_{i}+\sum_{k=1}^{j} S_{i, k}
$$

Then, the relevant condition in A6 becomes: $Q_{i}(j)>Q_{j}(j)$ for all $i<j$. The Proposition claims, with A6 and the other assumptions holding, there exists an equilibrium in which the sellers set their prices one by one, from seller 1 to seller $n$ as long as the cost of delay is negligible. To prove the claim, suppose that seller $i$ becomes the $j$-th mover $(i<j)$ and check whether she can improve her profit by doing so. Facing the deviation of seller $i$, seller $i+1$ lowers her price to induce further price cuts by the players after her and eventually to prevent seller $i$ from gaining an extra profit. Note that sellers 1 to $i-1$ are not affected by the deviation, and thus keep their prices at the maximum level $r$ as usual. Also, sellers $j+1$ to $n$ may be affected, but can keep the switchers because they have lower opportunity costs and later-mover advantages. Thus, we focus on the incentives of sellers $i$ to $j$ and whether seller $i$ can attract additional switchers.

Let us suppose for a moment that if seller $i$ fails to attracts $(j-1)$ groups of switchers altogether, she rather chooses to serve only $(i-1)$ groups of switchers at the price $r$ and earns a profit $\pi_{i}=$ $Q_{i}(i) \cdot r-j \varepsilon$. To keep the switchers, seller $j$ must set a price $p_{i}^{i=j}$ satisfying the following condition:

$$
r \cdot Q_{i}(i) \geq p_{i}^{i=j} \cdot Q_{i}(j)
$$

This is the incentive condition for seller $i$, and we read $p_{i}^{i=j}$ as the price set in the incentive condition for seller $i$ when seller $i$ is the $j$-th mover. Define $p_{i}^{i=j}$ as the maximum price that seller $j$ can charge while keeping $(j-1)$ groups of switchers, i.e., $p_{i}^{i=j}=r \cdot Q_{i}(i) / Q_{i}(j)$.

Next, we examine whether seller $j$ has an incentive to post such a low price. The condition for seller $j$ to do so is:

$$
p_{i}^{i=j} \cdot Q_{j}(j) \geq p_{j}^{i=j} \cdot\left[Q_{j}(j)-S_{i, j}\right]
$$

The left-hand-side of the inequality is the profit when seller $j$ wins $(j-1)$ groups of switchers as supposed, and the right-hand-side is the profit when seller $j$ 'accommodates' seller $i$ (i.e., giving up $\left.S_{i, j}\right)$. As before, $p_{j}^{i=j}$ is defined the maximum price that seller $(j-1)$ can charge to prevent seller $j$ from accommodating seller $i$. Similarly, we consider the incentive condition for seller $(j-1)$ : 


$$
p_{j}^{i=j} \cdot Q_{j-1}(j-1) \geq p_{j-1}^{i=j} \cdot\left[Q_{j-1}(j-1)-S_{i, j-1}\right]
$$

We keep recursively defining the maximum price that each seller can charge to reach the condition for seller $(i+1)$ :

$$
p_{i+2}^{i=j} \cdot Q_{i+1}(i+1) \geq r \cdot\left[Q_{i+1}(i+1)-S_{i, i+1}\right]
$$

If this condition holds, seller $(i+1)$ has an incentive to lower the price to induce further prices cuts by the other sellers. Using the equality incentive conditions of sellers $i$ and $i+2$ to $j$, we can rewrite the condition for $(i+1)$ as:

$$
\frac{Q_{i}(i)}{Q_{i}(j)} \cdot \frac{Q_{j}(j)}{Q_{j}(j)-S_{i, j}} \cdot \frac{Q_{j-1}(j-1)}{Q_{j-1}(j-1)-S_{i, j-1}} \ldots \frac{Q_{i+1}(i+1)}{Q_{i+1}(i+1)-S_{i, i+1}} \geq 1
$$

Because by $\mathrm{A} 6, Q_{i}(k)>Q_{k}(k)$ for all $i<k$, then

$$
\frac{Q_{k}(k)}{Q_{k}(k)-S_{i, k}}>\frac{Q_{i}(k)}{Q_{i}(k)-S_{i, k}} .
$$

Also note that for all $i<k$,

$$
Q_{i}(k)-S_{i, k}=L_{i}+\sum_{l=1}^{k} S_{i, l}-S_{i, k}=L_{i}+\sum_{l=1}^{k-1} S_{i, l}=Q_{i}(k-1) .
$$

Hence, the left-hand-side of the incentive condition for $(i+1)$ is:

$$
\begin{aligned}
& \frac{Q_{i}(i)}{Q_{i}(j)} \cdot \frac{Q_{j}(j)}{Q_{j}(j)-S_{i, j}} \cdot \frac{Q_{j-1}(j-1)}{Q_{j-1}(j-1)-S_{i, j-1}} \ldots \frac{Q_{i+1}(i+1)}{Q_{i+1}(i+1)-S_{i, i+1}} \\
& >\frac{Q_{i}(i)}{Q_{i}(j)} \cdot \frac{Q_{i}(j)}{Q_{i}(j)-S_{i, j}} \cdot \frac{Q_{i}(j-1)}{Q_{i}(j-1)-S_{i, j-1}} \ldots \frac{Q_{i}(i+1)}{Q_{i}(i+1)-S_{i, i+1}} \\
& =\frac{Q_{i}(i)}{Q_{i}(j)} \cdot \frac{Q_{i}(j)}{Q_{i}(j-1)} \cdot \frac{Q_{i}(j-1)}{Q_{i}(j-2)} \ldots \frac{Q_{i}(i+1)}{Q_{i}(i)}=1
\end{aligned}
$$

That is, the incentive condition for seller $(i+1)$ holds. In other words, seller $(i+1)$ is willing to trigger a chain of price-cuts which make seller $i$ 's deviation unprofitable.

To derive the incentive condition for seller $i$, we assumed that if seller $i$ fails to attracts $(j-1)$ groups of switchers altogether, she rather chooses to serve only $(i-1)$ groups of switchers at the price $r$. The above analysis shows that there exists a price $p_{i+1}^{i=j}$ which makes seller $j$ refuse to accommodate seller $i$. Similarly, there exists a price $p_{i+1}^{i=j-1}$ which makes seller $(j-1)$ refuse to accommodate seller $i$, and there also exist $p_{i+1}^{i=j-2}, p_{i+1}^{i=j-3}$, and so on. By choosing the lowest one amongst these, seller $(i+1)$ can make all the sellers from $(i+2)$ to $j$ not to accommodate seller $i$, and the incentive conditions imply that doing so is more profitable for seller $(i+1)$ herself. Q.E.D. 


\section{TABLES 1-4}

Table 1. Proportions of Loyal Consumers and Switchers

\begin{tabular}{lccccccc}
\hline & Tesco & Asda & Sainsbury & Morrisons & M\&S & Waitrose & Co-op \\
\hline Tesco & 0.413 & 0.179 & 0.226 & 0.186 & 0.155 & 0.184 & 0.238 \\
Asda & 0.186 & 0.427 & 0.184 & 0.258 & 0.163 & 0.066 & 0.195 \\
Sainsbury & 0.175 & 0.137 & 0.360 & 0.123 & 0.373 & 0.287 & 0.165 \\
Morrisons & 0.158 & 0.209 & 0.134 & 0.379 & 0.120 & 0.088 & 0.176 \\
M\&S & 0.008 & 0.008 & 0.025 & 0.007 & 0.077 & 0.043 & 0.012 \\
Waitrose & 0.015 & 0.005 & 0.031 & 0.009 & 0.069 & 0.285 & 0.022 \\
Co-op & 0.044 & 0.034 & 0.039 & 0.038 & 0.043 & 0.048 & 0.191 \\
\hline \hline $\begin{array}{l}\text { Indicative } \\
\text { LS ratio }\end{array}$ & 0.704 & 0.745 & 0.563 & 0.610 & 0.083 & 0.399 & 0.236 \\
\hline
\end{tabular}

Source: Authors' calculations 
Table 2. Pairwise test results on price changes involving identical monetary amounts

\begin{tabular}{|c|c|c|c|c|c|c|c|c|c|c|c|c|c|c|c|c|c|c|c|c|c|}
\hline & \multicolumn{21}{|c|}{ Retailer pair X-Y using regular prices } \\
\hline & $\mathrm{T}-\mathrm{S}$ & T-A & $\mathrm{T}-\mathrm{M}$ & T-MS & $\mathrm{T}-\mathrm{W}$ & $\mathrm{T}-\mathrm{CF}$ & S-A & S-M & S-MS & $\mathrm{S}-\mathrm{W}$ & $\mathrm{S}-\mathrm{CF}$ & A-M & A-MS & $\mathrm{A}-\mathrm{W}$ & $\mathrm{A}-\mathrm{CF}$ & M-MS & $\mathrm{M}-\mathrm{W}$ & $\mathrm{M}-\mathrm{CF}$ & MS-W & MS- & W-CF \\
\hline $\mathrm{X}$ leads up & 64 & 22 & 31 & 32 & 31 & 23 & 11 & 11 & 60 & 53 & 21 & 24 & 15 & 18 & 11 & 17 & 16 & 14 & 13 & 12 & 10 \\
\hline Simultaneous up & 45 & 38 & 14 & 9 & 9 & 7 & 15 & 21 & 20 & 41 & 12 & 22 & 8 & 6 & I & 0 & 5 & 5 & 27 & 12 & 8 \\
\hline Observed proportion & 0.587 & 0.367 & 0.689 & 0.78 & 0.775 & 0.767 & 0.423 & 0.344 & 0.75 & 0.564 & 0.636 & 0.522 & 0.652 & 0.75 & 0.611 & 0.739 & 0.762 & 0.737 & 0.325 & 0.5 & 0.556 \\
\hline $\mathrm{p}$ value & $0.042 *$ & 0.986 & $0.008 *$ & 0* & 0* & 0.003* & 0.837 & 0.975 & 0* & 0.128 & 0.081 & 0.441 & 0.105 & 0.011* & 0.24 & $0.017 *$ & $0.013^{*}$ & $0.032 *$ & 0.992 & 0.581 & 0.407 \\
\hline Y leads up & 16 & 18 & 12 & 7 & 7 & 7 & 25 & 16 & 5 & 6 & 7 & 16 & 7 & 3 & 5 & 10 & 6 & 4 & 25 & 7 & 10 \\
\hline Simultaneous up & 45 & 38 & 14 & 9 & 9 & 7 & 15 & 21 & 20 & 41 & 12 & 22 & 8 & 6 & 7 & 6 & 5 & 5 & 27 & 12 & 8 \\
\hline Observed proportion & 0.262 & 0.321 & 0.462 & 0.438 & 0.438 & 0.5 & 0.625 & 0.432 & 0.2 & 0.128 & 0.368 & 0.421 & 0.467 & 0.333 & 0.417 & 0.625 & 0.545 & 0.444 & 0.481 & 0.368 & 0.556 \\
\hline $\mathrm{p}$ value & 1 & 0.998 & 0.721 & 0.773 & 0.773 & 0.605 & 0.077 & 0.838 & 1 & 1 & 0.916 & 0.872 & 0.696 & 0.91 & 0.806 & 0.227 & 0.5 & 0.746 & 0.661 & 0.916 & 0.407 \\
\hline $\mathrm{X}$ leads down & 48 & 9 & 19 & 11 & 10 & 5 & 5 & 11 & 45 & 48 & 7 & 23 & 6 & 6 & 3 & 6 & 8 & 5 & 13 & 4 & 5 \\
\hline Simultaneous down & 15 & 15 & 13 & 1 & 2 & 2 & 3 & 13 & , & 13 & 6 & , & 2 & 3 & 1 & 6 & 6 & 4 & 12 & 2 & 2 \\
\hline Observed proportion & 0.762 & 0.375 & 0.594 & 0.917 & 0.833 & 0.714 & 0.625 & 0.458 & 0.833 & 0.787 & 0.538 & 0.719 & 0.75 & 0.667 & 0.75 & 0.5 & 0.571 & 0.556 & 0.52 & 0.667 & 0.714 \\
\hline $\mathrm{p}$ value & 0* & 0.924 & 0.189 & $0.003 *$ & 0.019* & 0.227 & 0.363 & 0.729 & $0 *$ & 0* & 0.5 & $0.01 *$ & 0.145 & 0.254 & 0.313 & 0.613 & 0.395 & 0.5 & 0.5 & 0.344 & 0.227 \\
\hline Y leads down & 10 & 19 & 5 & 6 & 5 & 5 & 13 & 14 & 3 & 5 & 5 & 6 & 1 & 3 & 4 & 1 & 2 & 4 & 13 & 7 & 7 \\
\hline Simultaneous down & 15 & 15 & 13 & 1 & 2 & 2 & 3 & 13 & 9 & 13 & 6 & 9 & 2 & 3 & 1 & 6 & 6 & 4 & 12 & 2 & 2 \\
\hline Observed proportion & 0.4 & 0.559 & 0.278 & 0.857 & 0.714 & 0.714 & 0.813 & 0.519 & 0.25 & 0.278 & 0.455 & 0.4 & 0.333 & 0.5 & 0.8 & 0.143 & 0.25 & 0.5 & 0.52 & 0.778 & 0.778 \\
\hline $\mathrm{p}$ value & 0.885 & 0.304 & 0.985 & 0.063 & 0.227 & 0.227 & 0.011* & 0.5 & 0.981 & 0.985 & 0.726 & 0.849 & 0.875 & 0.656 & 0.188 & 0.992 & 0.965 & 0.637 & 0.5 & 0.09 & 0.09 \\
\hline
\end{tabular}

Note: $*$ indicates statistical significance at $95 \%$ or higher confidence level.

Source: Authors' calculations 
Table 3. Single-handed leadership refinement for group (X,Y,Z)

\begin{tabular}{|c|c|c|c|c|c|c|c|c|c|}
\hline \multirow{2}{*}{$\bar{X}$ leads up $\mathrm{Z}$ alone } & $(\mathrm{T}, \mathrm{A}, \mathrm{S})$ & \multicolumn{8}{|c|}{$(\mathrm{T}, \mathrm{S}, \mathrm{MS})(\mathrm{T}, \mathrm{M}, \mathrm{MS})(\mathrm{S}, \mathrm{M}, \mathrm{MS})(\mathrm{T}, \mathrm{A}, \mathrm{W})(\mathrm{A}, \mathrm{M}, \mathrm{W})(\mathrm{T}, \mathrm{M}, \mathrm{W})(\mathrm{T}, \mathrm{M}, \mathrm{CF})(\mathrm{T}, \mathrm{S}, \mathrm{W})$} \\
\hline & & & & & & & & & \\
\hline Leadership incidences & & 17 & 28 & 53 & 22 & 16 & 28 & 22 & \\
\hline Non-leadership incidences & & 15 & 4 & 7 & 9 & 2 & 3 & 1 & \\
\hline Observed proportion & & 0.531 & 0.875 & 0.883 & 0.71 & 0.889 & 0.903 & 0.957 & \\
\hline $\mathrm{p}$ value & & 0.43 & 0* & 0* & 0.015* & $0.001 *$ & $\mathbf{0}^{*}$ & 0* & \\
\hline \multicolumn{10}{|l|}{$\mathrm{Y}$ leads up $\mathrm{Z}$ alone } \\
\hline Leadership incidences & & 45 & 13 & 10 & 9 & 14 & 13 & 13 & \\
\hline Non-leadership incidences & & 15 & 4 & 7 & 9 & 2 & 3 & 1 & \\
\hline Observed proportion & & 0.75 & 0.765 & 0.588 & 0.5 & 0.875 & 0.813 & 0.929 & \\
\hline $\mathrm{p}$ value & & 0* & 0.025* & 0.315 & 0.593 & $0.002 *$ & 0.011* & 0.001* & \\
\hline \multicolumn{10}{|l|}{$\mathrm{X}$ leads down $\mathrm{Z}$ alone } \\
\hline Leadership incidences & 45 & 8 & & & & & & & 6 \\
\hline Non-leadership incidences & 3 & 3 & & & & & & & 4 \\
\hline Observed proportion & 0.938 & 0.727 & & & & & & & 0.6 \\
\hline $\mathrm{p}$ value & 0* & 0.113 & & & & & & & 0.377 \\
\hline \multicolumn{10}{|l|}{ Y leads down $\mathrm{Z}$ alone } \\
\hline Leadership incidences & 11 & 42 & & & & & & & 44 \\
\hline Non-leadership incidences & 3 & 3 & & & & & & & 4 \\
\hline Observed proportion & 0.786 & 0.933 & & & & & & & 0.917 \\
\hline $\mathrm{p}$ value & 0.029* & 0* & & & & & & & 0* \\
\hline
\end{tabular}

Note: * means statistically significant at $95 \%$ or higher confidence level.

Source: Authors' calculations

Table 4. Indirect leadership tests

\begin{tabular}{lccccc}
\hline & \multicolumn{5}{c}{ Retailer pair X-Y using regular prices (3-4 weeks) } \\
\cline { 2 - 6 } & T-MS & T-W & T-CF & A-MS & A-W \\
\hline X leads up & 14 & 6 & 11 & & \\
Simultaneous up & 9 & 9 & 7 & & \\
observed proportion & 0.609 & 0.4 & 0.611 & & \\
p value & 0.202 & 0.849 & 0.24 & & \\
\hline X leads down & 13 & 12 & & 8 & 5 \\
Simultaneous down & 1 & 2 & & 2 & 3 \\
observed proportion & 0.929 & 0.857 & & 0.8 & 0.625 \\
p value & $\mathbf{0 . 0 0 1 *}$ & $\mathbf{0 . 0 0 6 *}$ & & 0.055 & 0.363 \\
\hline
\end{tabular}

Note: * means statistically significant at $95 \%$ or higher confidence level.

Source: Authors' calculations 


\section{FIGURES 1-3}

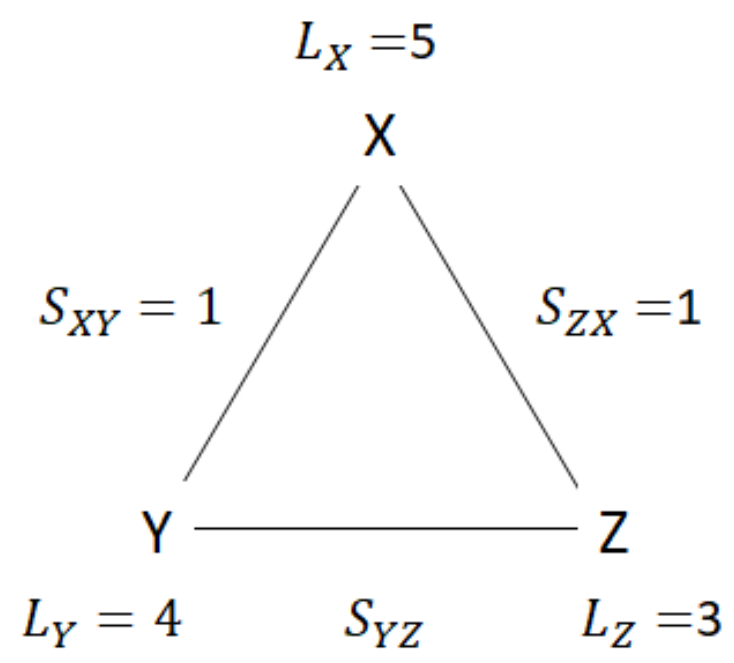

Figure 1. Triopoly example
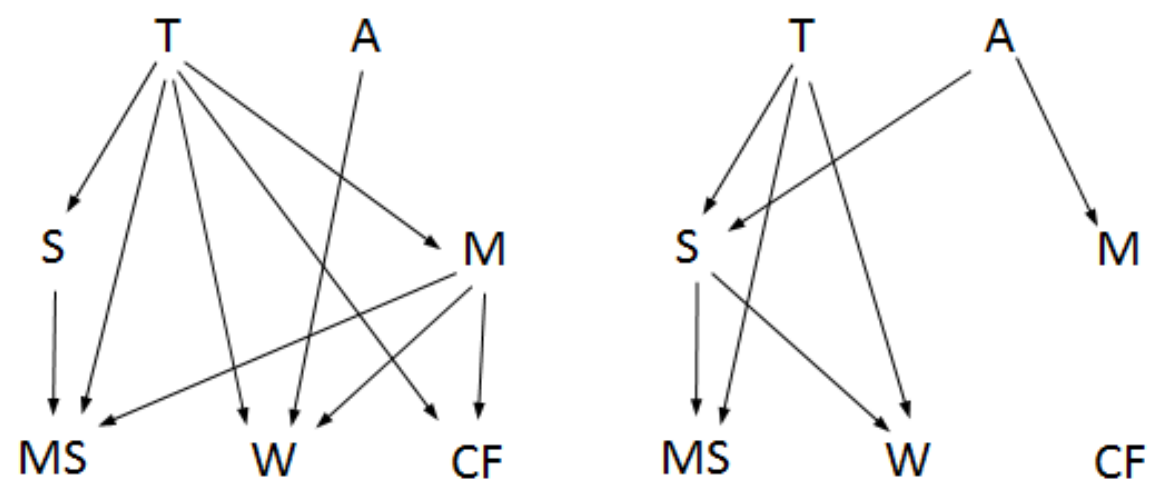

Figure 2. The price rise (left) and price cut (right) leaderships identified by the pairwise tests 

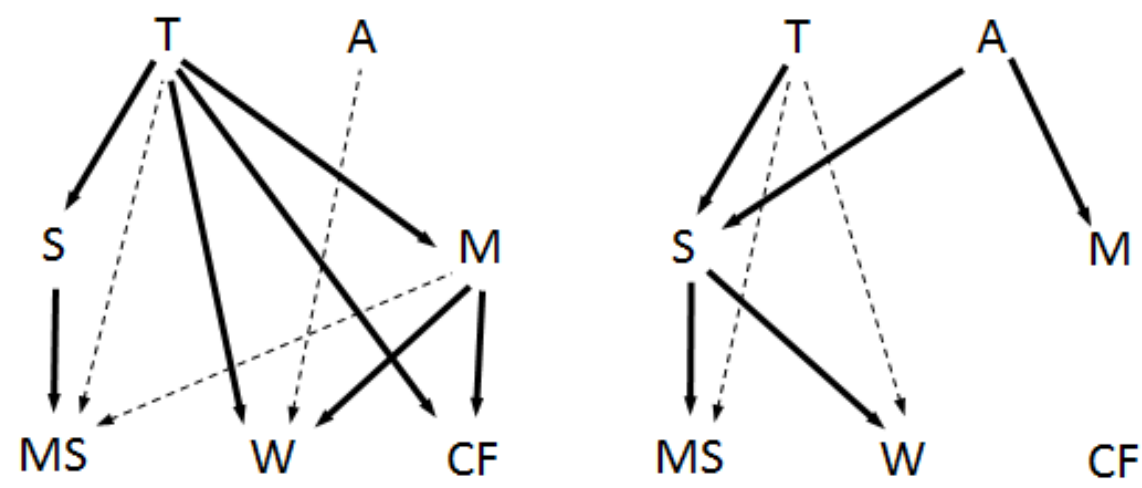

Figure 3. The price rise (left) and price cut (right) leaderships refined by the joint tests 